\title{
ADA compliance and teaching linguistics online
}

\author{
Shelby Miller*
}

\begin{abstract}
Only 8.8\% of faculty have reported receiving formal training for developing ADA (Americans with Disabilities Act) compliant online courses (Gould \& Harris, 2019), yet in any given semester, faculty may be required by federal law to make their course accessible for a student that has enrolled with a disability. Linguistics faculty face many of the same challenges (namely time and resources) as other disciplines with implementing ADA federal guidelines. However, there are further obstacles with linguistic specific topics (such as dialect illustrations, phonology, morphology) that require special attention when devising accessible material for those that are either visually or hearing impaired. Through the exploration of an undergraduate linguistics course (LING 2050: Language of Now), this paper reflects on best practices, suggested modifications, barriers in developing an ADA compliant online linguistics course, and presents a resource developed by the author aggregating resources that facilitate making a course ADA compliant.
\end{abstract}

Keywords. ADA; accessibility; linguistics; accommodations; online; higher education; inclusion

1. Introduction. Undergraduate and graduate linguistics courses have increasingly moved to online delivery as universities aim to provide a flexible classroom experience for students. While not every university offers their entire linguistics curriculum online, it is common to see online course options in linguistics even at universities with a majority of face-to-face course offerings. Most recently in 2020, due to COVID-19, the entire field of linguistics was challenged to explore ways in which linguistics could be taught remotely (fully online). Thus, even if the program was not fully online before, it now had to be.

An aspect of online teaching that has regularly been overlooked is that of accessibility. Accessibility in this paper refers to the Americans with Disabilities Act (ADA). As part of its application to higher education, the ADA (Section 508) specifically requires all electronic and information technology used in higher education teaching be accessible and inclusive for students with disabilities enrolled in the courses. Typically, the effort to make a course accessible occurs when a faculty member is notified that they need to make accommodations for a student enrolled in their course. However, some universities are now mandating all courses be accessible regardless of who is enrolled. Alarmingly, though only $8.8 \%$ of faculty have reported receiving formal training for developing ADA compliant online courses (Gould et al., 2019).

I sought to implement ADA best practices into an online undergraduate linguistics course. The experience revealed that many accessibility practices are simple to implement. Additionally, these practices support both disabled and non-disabled learners. However, there are several barriers that prevent linguists from creating fully accessible courses.

2. Justice, equity, and inclusion in accessible online instruction. By prohibiting the discrimination of individuals with disabilities, the ADA in turn promotes justice, equity, and inclusion for those individuals. When we think of accessibility in the online classroom, we often think they're mainly to serve someone with a severe visual or hearing impairment. Thus, we tend to

\footnotetext{
*Author: Shelby Miller, University of North Texas at Dallas (shelby.miller@untdallas.edu).
} 
think about the benefits of accessibility from a narrow scope, without realizing that accessibility measures create classroom equity for all students. In fact, there are many students in our classrooms that have forms of visual and hearing impairments that are not covered under the ADA. Specifically, 1 in 12 men are colorblind, $75 \%$ of adults use some sort of vision correction, $60 \%$ of Americans are far sighted (i.e., will have trouble reading), and 1 in 4 college students have hearing loss or hidden hearing loss that impacts their ability to discern speech (Caswell, 2015; Kian, 2020; Le Prell, Hensley, Campbell, Hall \& Guire, 2012; Liberman, Epstein, Cleveland, Wang, \& Maison; 2016; National Eye Institute, 2019). Apart from disabilities, accessibility features also benefit non-disabled students and second language learners. Research has shown that implementing ADA best practices, such as closed-captioning and transcripts, resulted in increased student engagement, and increased retention and comprehension of course content (Kent, Ellis, Peaty, Latter \& Locke, 2017; Markham, 2008; Rowland, 2007). When we focus on accessibility, we create an inclusive course experience that assists every student.

3. LING 2050: Language of Now. For this project, I used an undergraduate linguistics course called LING 2050: The Language of Now. LING 2050 is offered online every semester as a core curriculum course, thus students in this course come from many different majors. This course serves as a simplified introduction to linguistics, with a focus on sociolinguistic analysis and theories. Lectures are pre-recorded and the class is offered asynchronously. The course does not require a textbook, but instead relies on a variety of outside and self-generated instructional materials to teach. A summary of the instructional material diversity is provided in Table 1.

\begin{tabular}{ll} 
Instruction Type & Instructional Materials \\
\hline Learning Management System (LMS) & Canvas \\
Course Shell & Text \\
& Images (primarily ascetic) \\
& Links \\
& Videos \\
Readings & Book excerpts (PDFs) \\
& External websites (e.g., articles, surveys) \\
& Infographics \\
Lectures & Video recordings \\
& PowerPoint \\
& Prezi \\
& YouTube \\
& Panopto \\
& Podcasts \\
& EdPuzzle \\
Homework & Word documents \\
& Quizzes (multiple choice, short answer; \\
& hosted by LMS) \\
Discussion boards (hosted by LMS) & EdPuzzle \\
FlipGrid \\
Canva \\
Printed map of U.S. \\
\hline
\end{tabular}

Table 1. Summary of instructional materials used in LING 2050 
LING 2050 is taught by multiple faculty members in a given year, and the course design, objectives, and materials are shared.

4. Implementing ADA best practices. Through this experience, I learned that many of the accessibility changes faculty need to make (regardless of the linguistic topic being taught) are simple (see Table 2 for a summary of suggested simple fixes). By "simple", I mean they require a shallow learning curve. Changes such as this include enlarging font sizes, changing font type, adding alternative text to images, and replacing links with descriptive text (i.e., embedding website links into the page's text rather than providing complicated web addresses). Additionally, most of the changes implemented are long-term fixes, meaning once made, the changes will not have to be revisited each time the course is taught. This is a benefit for courses that are offered regularly where the instructional material doesn't change. Implementing ADA best practices does take a great deal of time, so it is beneficial to be reminded that one's effort creates permanent solutions.

\begin{tabular}{lll} 
Instructional Material & Simple Areas to Fix & Resource \\
\hline PowerPoints & Font & https://thada.org/powerpoints/ \\
& Read order & \\
& Color & \\
& Links & \\
& Images & \\
& Slide titles & \\
& Font & https://thada.org/course-shell/ \\
Course shell & Abbreviations & \\
& Hyperlinks & \\
& Color & \\
& Font & https://thada.org/word-docs/ \\
Word documents & Headings & \\
& Writable lines & \\
Links & Hyperlinks & https://thada.org/links/ \\
Images & Alternative Text & https://thada.org/images/ \\
\hline
\end{tabular}

Table 2. Summary of suggested simple fixes with resource links

This course utilized a wide variety of instructional materials (see Table 1), thus implementing ADA strategies required becoming familiar with ADA best practices for each of these items. For example, students in this course learn about the word "selfie" through the "2013: The Year of the Selfie" infographic (see accessible version: https://thada.org/infographics/). There were two accessibility issues with this piece. First, by nature, an infographic assumes a student can see, which excludes visually impaired students. Secondly, this infographic was a .jpeg (a picture file), which meant a visually impaired student could not rely on a screen reader to read the text. Online resources discussing how to make infographics accessible required expertise in HTML and $\mathrm{CSS}^{1}$, so alternatively, I provided a typed transcription of the infographic in a Word document alongside the image in the course. This would allow a screen reader to read the text and was a feasible alternative to learning markup languages.

The application of ADA features also helped improve the linguistic focus of this course. For example, in a lecture on affixation, the automated closed-captioning combined the morpheme

\footnotetext{
${ }^{1}$ CSS stands for "Cascading Style Sheets," which are used to format and style the layout of webpages.
} 
-ing with the previous word, rather than recognizing it as its own unit of speech in the context of the lecture (see Figure 1).

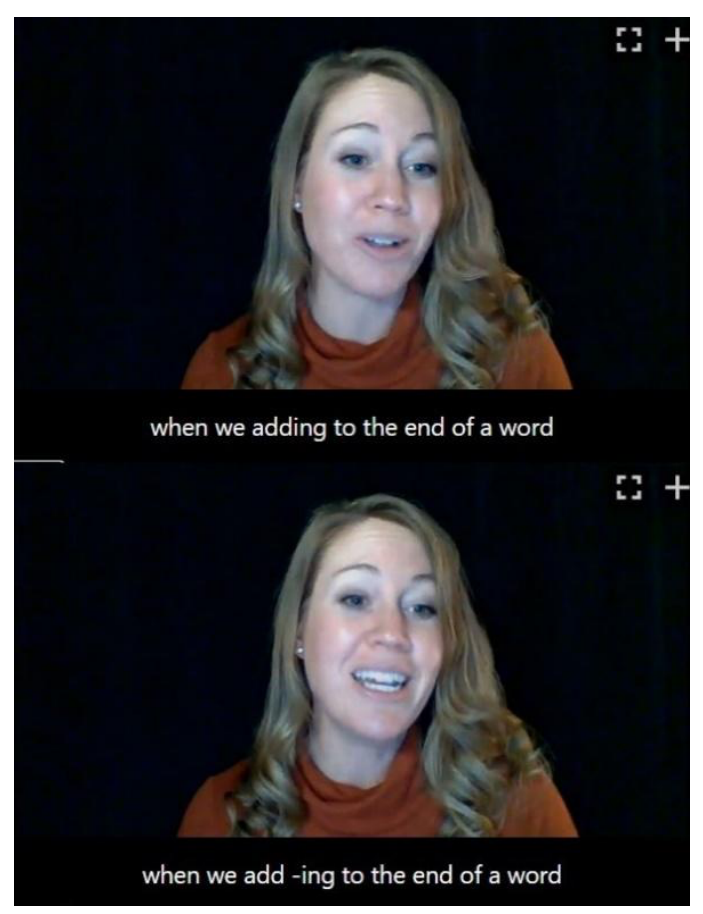

Figure 1. Automated closed-captioning versus edited closed-captioning

Caption errors like this regularly occurred with morphemes, phonemes, accent illustrations, and words from foreign languages. Editing the closed-captioning of my recorded lectures, rather than relying entirely on automated closed-captioning, allowed me to ensure that linguistics terms and concepts were correctly transcribed and communicated.

5. Barriers. There were three primary barriers in creating an accessible linguistics course. The first of which was the time commitment, the second was the ability to find resources, and the third pertained to specific issues in linguistics.

5.1. TIME. While I argue that many of the accessibility changes needed in courses are simple, one-time fixes, they are not necessarily easy to implement. Table 3 reflects the approximate time required for applying ADA changes to one week's worth of primary instructional materials. For example, adding closed-captioning or editing automated closed-captioning on a 20 -minute lecture can take several hours, and there were 1-2 lectures in each week of this 16-week course. Additionally, increasing the font size in the LING 2050 course shell was a simple accessibility fix, but the course had 147 pages, and each one of them required individual editing. This is because there is no functional global editing feature in Canvas that allows faculty to make a onetime universal change. Canvas does provide a built-in accessibility checker, however, this also had to be run for each individual page (i.e., 147 times). The implementation in Canvas, or other LMS providers, of features that facilitate making the course accessible would require petitioning from multiple universities or professional societies. The process of implementing ADA best practices into a course shell would be more time efficient for faculty if universities could head the conversations with LMS providers on these needs. 


\begin{tabular}{|c|c|c|c|}
\hline Instructional Material & Quantity & $\begin{array}{l}\text { Most Frequent ADA } \\
\text { Changes }\end{array}$ & $\begin{array}{l}\text { Time Implementing } \\
\text { ADA Best Practices }\end{array}$ \\
\hline $\begin{array}{l}\text { Pre-recorded lec- } \\
\text { ture(s) }\end{array}$ & 20-50 minutes & $\begin{array}{l}\text { Editing automated } \\
\text { closed-captioning }\end{array}$ & $3+$ hours \\
\hline PowerPoint & 12-15 slides & $\begin{array}{l}\text { Spacing and enlarg- } \\
\text { ing information, } \\
\text { adding alt. text to } \\
\text { images, modifying } \\
\text { slide titles }\end{array}$ & 30-40 minutes \\
\hline Word Documents & $\begin{array}{l}1 \text { multi-page as- } \\
\text { signment template }\end{array}$ & $\begin{array}{l}\text { Adding fillable form } \\
\text { fields, providing text } \\
\text { in place of visual in- } \\
\text { struction to } \\
\text { accommodate screen } \\
\text { readers }\end{array}$ & 20 minutes \\
\hline LMS pages & 9 pages & $\begin{array}{l}\text { Font size, adding alt. } \\
\text { text to images, modi- } \\
\text { fying hyperlinks, } \\
\text { removing abbrevia- } \\
\text { tions }\end{array}$ & $10-30$ minutes \\
\hline
\end{tabular}

Table 3. Weekly time commitment for applying ADA changes to primary instructional materials

5.2. LACK OF UNIFIED RESOURCES. There were no one-stop resources that could assist me in this process. I initially relied on institutional trainings and staff to guide me in the right direction. Their knowledge base was extremely helpful, but they could not address some of the unique challenges I was facing, especially pertaining to linguistic related topics (see 5.3 Challenges for the Field of Linguistics). I turned my attention to online resources looking for answers that pertained to not only accessibility, but accessibility as it related to every piece of instructional material used in the course. This required combing through hundreds of websites.

5.3. CHALLENGES FOR THE FIELD OF LINGUISTICS. There were many complications effectively implementing ADA compliant practices for teaching linguistics. While I was able to resolve certain issues pertaining to morphemes, phonemes, and dialects in the closed-captioning, these same topics created unavoidable challenges outside of recorded lectures. For example, when I illustrated the phoneme [p] in a written lecture, I discovered that assistive screen readers would pronounce [p] as [pi]. I also had this challenge with screen readers and some bound morphemes, such as "tri-" (e.g., "trifold"), which would be pronounced as [tii]. Regarding dialects, it was complicated to illustrate dialect variations effectively in written text and in audio form (e.g., YouTube videos). Screen readers would often misread the text which in turn yielded an unsuccessful demonstration of the dialect, and the majority of YouTube videos didn't provide accurate closed-captioning. In these cases, the only solutions are to either produce the closed-captioning and submit it to YouTube or create a transcript of the video to provide to students. Both alternatives require a great deal of time.

6. Good faith effort. The endeavor to create an ADA compliant online linguistics course proved to be useful but not entirely successful. On one hand, the ADA best practices I was able to implement did improve the accessibility and inclusiveness of the course, but this experience also 
showed that it is currently impossible for one faculty member to ensure every aspect of a course is accessible (see section 5. Barriers). Therefore, the current goal cannot be full accessibility, but rather putting forth a good faith effort, by making accessible what can be made accessible, and by accepting the inaccessibility that is outside the control of the faculty member. To assist other faculty members in their good faith efforts, and to work towards a unification of resources, I have developed the Teaching Headquarters for the Americans with Disabilities Act (THADA), ${ }^{2}$ to provide faculty with self-training and guidance while making their courses more accessible and inclusive for every student. However, it needs to be clear, without serious institutional support putting pressure on LMS providers to make ADA implementation easier, creating an ADA compliant course is not a feasible responsibility for a faculty member. Large universities especially can support this by negotiating with vendors. Institutions should also consider offering faculty course release time to make these changes in their courses or seek outside vendors to assist faculty with the time-consuming practices (e.g., closed-captioning).

\section{References}

Caswell, Jessica. 2015. What is nearsightedness and farsightedness. The Vision Blog. https://www.vspdirect.com/vision-hub/what-is-nearsightedness-and-farsightedness.

Gould, Rob \& Sarah P. Harris. 2019. Research brief: Higher education and the ADA. ADA National Network Knowledge Translation Center. 1-6. https://adata.org/research_brief/higher-education-and-ada.

Kent, Mike, Katie Ellis, Gwyneth Peaty, Natalie Latter \& Kathryn Locke. 2017. Mainstreaming captions for online lectures in higher education in Australia. Curtin University, AU: National Centre for Student Equity in Higher Education. https://www.ncsehe.edu.au/wpcontent/uploads/2017/04/MainstreamingCaptions_FinalReport.pdf.

Kian, Meena. 2020. A change in worldview: Vision correction explained. SQonline. https://sqonline.ucsd.edu/2020/06/a-change-in-worldview-vision-correction-explained/.

Le Prell, Colleen G., Brittany N. Hensley, Kathleen C. M. Campbell, James W. Hall \& Kenneth Guire. 2012. Evidence of hearing loss in a 'normally-hearing' college-student population. International Journal of Audiology 50(1). 21-31. https://doi.org/10.3109/14992027.2010.540722.

Liberman, Charles M., Michael J. Epstein, Sandra S. Cleveland, Haobing Wang \& Stéphane F. Maison. 2016. Towards a differential diagnosis of hidden hearing loss in humans. PloS One 11(9). e0162726. https://doi.org/10.1371/journal.pone.0162726.

Markham, Paul. 2008. Captioned videotapes and second-language listening word recognition. Foreign Language Annals 32(3). 321-328. https://doi.org/10.1111/j.1944-9720.1999.tb01344.x.

National Eye Institute. 2019. Color blindness. https://www.nei.nih.gov/learn-about-eyehealth/eye-conditions-and-diseases/color-blindness.

Rowland, L. James. 2007. Closed-captioning videos and the ESL classroom: A multi-sensory approach. Journal of Adult Education 36(2). 35-39. https://eric.ed.gov/?id=EJ891068.

\footnotetext{
2 Teaching Headquarters for the Americans with Disabilities Act (https://www.thada.org).
} 